\title{
Revitalization of Tribal Economy through Sustainable Tasar Culture in Maharashtra
}

\author{
I. I. Hugar, K. Sathyanarayana ${ }^{1}$, A. B. Pande \\ BAIF Development Research Foundation, Central Research Station, Urulikanchan-412202, Pune Maharashtra, India. \\ ${ }^{1}$ Central Silk Board, Ministry of Textiles, Govt. of India, BTM Layout, Bangalore-560 016, Karnataka, India
}

\begin{abstract}
Tribal communities mostly women belonging to Katkaria, Maria Gond and Kolam are among the primitive tribal Groups (PTGs) besides Deewar belonging to Backward Communities, who practice tasar silkworm rearing as part of their tradition and culture in the state of Maharashtra. Gadchiroli and Chandrapur are dominated by these communities who depend on tasar for their livelihood and are reported endemic poverty. BAIF Development Research Foundation, an NGO has initiated different livelihood progarmmes in north- east part of Maharashtra with special emphasis on tribal development through exploring appropriate livelihoods options such as Wadi (Horticulture orchard), improved agriculture, watershed, women development, livestock development, community development, Health \& hygiene and non timber forest produce (NTFP) and integrating them for income augmentation. Result based interventions focused at strengthening traditional activity by appropriate technology inputs viz training, capacity building, demonstration, exposures, formation of activity groups, scientific rearing of silkworms, host plantation utilization and management, seed production, post cocoon activities, value addition, natural resource management and marketing linkage. Efforts on these lines helped to check distress migration and rejuvenating degraded natural recourses, which was also successfully demonstrated. Consistent efforts of BAIF over the past 7 to 8 years have created a replicable model in promotion of Tasar based livelihoods indicating an estimated incremental annual income of over Rs. 8000- 10000/- from tasar silkworm rearing and Rs. 2000- 4000/- additional income through allied activities like vegetable cultivation was documented. This has further gained momentum with support from Central Silk Board (CSB) and Ministry of Rural Development (MoRD), Govt. of India, under multistate tasar based livelihood project under Mahila Kisan Sashaktikarna Pariyojana (MKSP- NTFP) being implemented by BAIF in Maharashtra. The project planned to provide over 5800 sustainable livelihoods for the marginalized households, specially seeking involvement of Scheduled tribe communities and women in Gadchiroli, Gondia, Chandrapur and Yevotmal district of Maharashtra. The project will strengthen and enhance livelihoods with improved quality of tribal through training, capacity building and provide appropriate infrastructure facility for augmenting income and employment opportunities. Project models planned in institution and capacity building besides integrating various livelihood options tried at pilot scale by the NGO on a scale.
\end{abstract}

Keywords: Vanya, Livelihood, Tribal, Tasar, Holistic approach, Natural resource

\section{Introduction}

Tasar sericulture plays a vital role and became an integral part of tribals, practiced by over 1.5 lakh tribal population in nine states of India, including Maharashtra. In Maharashtra, tasar sericulture is being practiced in the districts of Gondia, Gadchiroli and Chandrapur. High concentration of scheduled tribes and high dependence on forest based livelihood, active ultra leftist forces with predominantly rural and depict abject poverty are the key features of this region. In view of the above, BAIF, an NGO initiated tasar interventions integrating with other allied livelihood activities focusing on Natural Resource Management. Such integrated approach keeps community engaged with year round income.

BAIF in its innovative development approach focuses on 5J model such as, Jal (water), Jameen (soil), Jungle (Agroforestry), Janawar (livestock) and Jan (human). BAIF believes in holistic and sustainable development of the family with participation of both men and women members of participating family by adopting appropriate technology interventions. Systematic integration of 5-J concept could provide year round employment and income generation, which ultimately result in socio-economic development of the rural families. In case of tribal development, BAIF started intervention on livelihoods with combination of several activities like watershed development, tree based farming, plantation of horticulture orchards (WADI), Health and nutrition, focusing on women and Child health, improved agriculture etc along with tasar intervention. Such approach helps rural commune by adding economic value, harmonizing environment and building strong community.

\section{Methodology}

Socio-economical status of Gadchiroli and Chadrapur region

In Ettapalli and Gadichiorli lowest literacy was observed ( $40 \%$ in men and $23 \%$ in women) and $96 \%$ of the families earns less than Rs. 20000/ per annum. However, It was interesting to note that, the percentage of migration in Gadchiroli was only $2 \%$, this might be due to abundant availability of Tendu leaves (Diospyros malanoxylon) and Mahuva ( Madhucaindica) which are main source of earning. As far as livestock is concern, Gadchiorli region though having large herd composition with he-buffaloes and piggery but did not proved major income generating activity.

\section{Problem Analysis}

Forest dependent livelihoods of these tribal families have been adversely affected due to heavy deforestation and dwindling forest produce. Certain other challenges faced are low soil cover, increased frequency of shifting cultivation, heavy soil erosion, high input costs, problems of pests and diseases and limited credit availability. Majority of the 


\section{International Journal of Science and Research (IJSR) \\ ISSN (Online): 2319-7064}

Index Copernicus Value (2013): 6.14 | Impact Factor (2014): 5.611

families depend upon rain fed agriculture. Besides, this, the road connectivity and transportation are severely disturbed during heavy rains for at least 4-5 months. The prevailing social practices of high expenditure for family functions like weddings and the intermittent medical expenses for one or the other member of the family further stretch the available financial resources to the limit and force the families to avail credit at exorbitant interest rates from the unscrupulous money lenders. Gadchiroli is badly affected by this menace and many families are being forced into this form of protest due to financial plight and extremist influence.

Most of the tribals live in the forest or in the fringe areas though, agriculture is the primary livelihood of these people. However considering the low yields of paddy in the rainfed areas, people look for additional livelihood opportunities. Tasar rearing starts after the agriculture season i.e., September, when the opportunity cost of labour remains low. The rearers traditionally rear Tasar silkworms in the nearby forest areas. On an average, the entire family of the rearers spends 80-90 days in silkworm rearing in the forest land.

\section{Opportunities}

BAIF strongly believes in holistic development of the family and predominantly working with the people by designing appropriate and innovative developmental model in consultation with farming community for sustainability of the programme. It is thus confirmed that the choice of the livelihood for most farming families has been narrowed down considerably and there is a need to widen this base to alleviate the distress situation. Hence efforts have been made to introduce alternate seasonal livelihood activities such as lac, tasar, water chestnut \& fish cultivation, rock bee honey harvesting etc. have shown promising results. Tribals involve in farming activity for only 4-6 months in year. After rainy season most of tribals engage in collection of NTFP, hunting and migrate for labor work. It was noticed that, the tribal communities particularly youths have shown keen interest in learning new activities and supplement their agriculture income. Involvement of tribal families in one or more activity during non farming months ensures steady source of income, employment round the year. It also helps conserve forest, prevent migration and improve quality of life.

\section{BAIF interventions in promotion of Tasar based livelihoods}

BAIF initiated tribal development through different livelihood activities involve tribal in plantation of WADI Mango orchards, construction of water body (Water resources development like farm pond, diverting channels check dams etc, capacity building through training and exposures, importance and economics of tree based farming, management of forest medicinal and economical trees etc. and focused on vanya sericulture which provided additional income to the tribal family by creating employment to the whole family. By considering the following objectives in mind BAIF initiated tasar sericulture based livelihoods activity.

\section{Objectives:}

- To increase annual income of tribal families through tasar sericulture

- To strengthen community institutions (CBO's)

- To conserve and regenerate natural resources

- To build capacity and enterprises development in Tasar sericulture.

- Design, development and adoption of innovative integrated approaches in promotion of Tasar enterprises.

- To increase employment, income and stop distress migration.

- To improve social status, assured food security and quality of life.

- Sustainable utilization of natural resources without harming other components.

\section{BAIF - Towards tribal mahila kisan development}

BAIF initiated different livelihood progarmmes in Chandrapur, Gondia, Gadchiroli and Nagpur districts during 2004, focusing on tribal development through appropriate region specific interventions with support had from National Agriculture Innovation Project for livelihood improvement and Catalytic Development Project from Central Silk Board, State Sericulture Department. Sir Ratan Tata Trust (SRTT) has opened a new ray of hope in Tasar based livelihood promotion in Maharashtra. The strategies viz. Ensuring food and nutrition security by Improved agriculture and vegetable cultivation round the year in the backyard was introduced, To promote health security, participants were trained to raise level of awareness on health, hygiene and nutrition. Different health programme sponsored by of Govt. were tied with project.

Since women are the back bone of the tribal community and play a pivotal role in both household and economic activities, still with lower social status. Organizing women into SHGs, formation of Tasar Vikas Samiti and building capacity through training and exposure in order to make them driving force of the village were taken up to address upgradation of women knowledge and skills. While credit would be mobilized from the SHG savings for routine activities and for activities like seed production, the groups would approach the financial institutions to mobilize credit for the working capital requirements, which would be facilitated by BAIF.

Most of the tasar rearers take up rearing without technical packages and earn income in the range of Rs. 3000 to Rs. 4000/-, against income potential of over Rs. 10000/-. Initiatives under NAIP and other projects tried to build all the required linkages so as to make available critical inputs and services to the producers so as to increase their income levels and iprove their quality of life.

\section{Implementation of Tasar sericulture livelihood initiatives}

With the financial support from NAIP, CDP and SRTT, BAIF initiated tasar based livelihood activities in Chandrapur (Pombhurna and Jiwati) and Gadchiroli (Ettapalli) region since 2008-09, consistent efforts were 


\section{International Journal of Science and Research (IJSR) \\ ISSN (Online): 2319-7064}

Index Copernicus Value (2013): 6.14 | Impact Factor (2014): 5.611

made to identify potential villages based on availability of natural tasar host plantation. Efforts were made to convince tribals through various methodologies viz., training, capacity building, demonstration, exposures, and formation of activity groups, scientific rearing of silkworms, host plant management, seed production, post cocoon processes, value addition and marketing.

\section{Training, Exposure and capacity building}

Training and capacity building was key component in successful implementation of project activities. The training included field demonstration of tasar chawki rearing management, host plantation management, disease, pest and predator control measures; cocoon harvesting, processing and preservation followed by exposure visits to Regional Research Centers of CSB and BAIF Central Research Station, Urulikanchan, Pune. Interaction with experts and progressive farmers play a pivotal role in changing participants' mindset and confidence building. During training period farmers were provided detailed information on technical aspects viz., leaf: Dfl ratio, plantation management, risk involved in late age silkworm rearing, corrective and preventive measures to avoid disease incidence, disease monitoring, and entrepreneurship opportunity in tasar sericulture etc. Scientific method of tasar egg hatching and chawki rearing training were also provided to project participants and their practice was closely monitored for desired output. Exposure visits also were conducted to learn and internalize innovative models appropriate to tribal areas and further replication.

\section{Involvement Tribal youth in Tasar seed multiplication activity}

Tribal youth shown keen interest in learning new activities and supplement their agriculture income and other interested tribal families who were interested to take up one or more activity to get year round income were selected for the seed production activity in consultation with the Kosa Group at village level. BAIF identified potential youths and trained in tasar seed production i.e., grainage activity. Selected youth were imparted with technical training in grainage activity which include selection of seed cocoons, seed cocoon storage, moth emergence, moth coupling, egg production, mother moth examination for disease detection etc. Grainage house and grainage equipment were provided through project support and Government linkages. The DFL's produced preferably bivoltine laying from grainage will supply to other participants at pre-decided price through Kosa group.

\section{Promotion of Post cocoon activity}

The potential members preferably women from self-help group who may involve in tasar silkworm rearing, and seed multiplication are selected in consultation with Kosa group and trained in practical aspects post cocoon processes like reeling, spinning and matka spinning by subject experts. The cocoons provided by Kosa group for post cocoons processing on job work basis.

\section{Incremental income generated from tasar and other allied activities}

Efforts made through continuous orientation, training, demonstration, and exposure along with supportive activities helped participants to get an incremental annual income of over Rs. 8000-10000/- per crop from tasar silkworm rearing andRs. 2000 to 4000/- additional income through allied activities like vegetable cultivation, NTFP collection etc. Due to BAIF innovative approach for holistic development of the participating family, several initiatives like water resource development for agriculture practices providing improved seeds, package of practices, field demonstrations and development of existing water body's for its effective utilization etc were demonstrated, due to which an increase of over $20 \%$ in agriculture production resulting in food security. It is expected that the established WADI's -Mango and cashew orchards would start yielding by 2014-15, which could become a major source of income to the participating families. Moreover various interventions create an affection and ownership towards their piece of land, improved biodiversity and conservation of natural resources. Incremental incomes through other activities do not only sustain, but also increase due to capacity utilization, improvement in quality due to increased skill levels. Further, the costs of production have come down increasing earnings due to technology intervention and capacity building. Also due to linkages amongst the activity groups dependency on others will come down which reduce the incidental expenditure to take up various activities.

\section{Impact of the programme:}

1) Employment and income generation through Tasar based livelihood has created awareness \& willingness to accept technology among neighbouring villagers.

2) Augment the need of quality disease free layings by project participants

3) Improve in the cocoon productivity and land fertility

4) Create sustainable livelihoods for resource poor families, especially small and landless.

5) Reduction in migration due to gain employment locally.

6) Influencing the policy makers for replication and upscaling of the model in other parts.

7) By visualizing the success from tasar rearing, participants willingly initiated block plantation in their available land.

8) Forest dwellers indirectly conserve natural forest by rearing tasar silkworms andnatural protection and improvement of biodiversity.

\section{Benefits beyond Project Beneficiaries}

- Check Soil erosion and improve soil fertility

- Rainwater percolation lead to better water retention in natural ponds

- Increase in tree density \& diversity improves biodiversity

- Host plantation contributes in carbon sequestration and earn carbon credits

- Increase in soil microbial diversity of different microbial taxa by tasar silkworm rearing activity 


\section{International Journal of Science and Research (IJSR) \\ ISSN (Online): 2319-7064}

Index Copernicus Value (2013): 6.14 | Impact Factor (2014): 5.611

Future opportunities and Strategy

During 2013-14, Central Silk Board (CSB) with Ministry of Rural Development (MoRD), Govt. of India, supported multistate tasar based livelihood project has been implemented in order to promote tasar sericulture based livelihoods in Maharashtra with the mission for uplifting tribal women under Mahila Kisan Sashaktikarna Pariyojana (MKSP- NTFP). The project planned to provide over 5800 sustainable livelihoods for the marginalized households, specially seeking involvement of Scheduled tribe communities and women in Gadchiroli and Gondia, Chandrapur and Yeotmal districts at an outlay of Rs. 12.035 crores shared by MoRD (Rs. 7.598 crores),CSB (Rs. 2.532 crores) and credit \& beneficiary (Rs 1.905 crores).

This project builds on the foundations of large scale social mobilization of women facilitated by BAIF and MSRLM's partners in Maharashtra and an array of livelihood propositions for the marginalized, based on Tasar sericulture that have been made standardized through decades of meticulous efforts by PRADAN with support from the Central Silk Board (CSB) under the special SGSY Projects in Bihar and Jharkhand. Main objective of the project is to augment silkworm seed production in private sector, nurturing Community Resource Persons and yarn conversion on pilot scale. Besides, the project envisages promoting integrated activities like improved Agriculture, vegetable cultivation and other best practices. The project is to facilitate rapid growth in the sub-sector of Tasar Sericulture through capacity building of poor tribal families to facilitate adoption of improved technologies and practices and enabling them to access mainstream markets to sustain the economic gains. The project also focus on design development \& product diversification to increase producer's share locally and disease monitoring to ensure higher productivity to achieve desired income levels. The total project investment per family is worked out at Rs. 20,784/- per family and project grant of Rs. 17,493/- per family of which about Rs. 7,922/- is invested in equipments, Rs. 4,176/- towards capacity building and Rs. 5,490/towards creation of common assets for participating families.

\section{Project Coverage}

The project cover 60 nursery farmers, 40 Nucleus Seed Rearers, 240 Basic Seed Rearers, 60 Private Graineurs, 2786 commercial rearers, 100 Reelers and 40 Spinners under the project. It is establish one Basic Seed Production Unit, 5 Rearers' Collectives and 4 Reelers' Collectives besides a Cocoon Bank with the project assistance. Besides, Project would focus on Design development \& diversification, disease monitoring, documentation etc.

\section{Project Output}

With this investment, it is proposed to raise 200 ha of food plants of tasar silkworms, 1750 ha. of natural host flora would be regenerated, 0.48 lakh dfls of basic seed \& 6.75 lakh dfls of commercial seed to be produced which will help in production of 211.78 lakh reeling cocoons to be produced during the project period. Finally an estimated $17005 \mathrm{kgs}$ of Tasar Raw silk would be produced under this project. It is also proposed to nurture and promote 82 nos. of Community Resource Persons for future expansion programmes.

Tasar sericulture activities under this project will provide an incremental income of Rs. 10,000 to Rs. 18,700 to a producer-family (silkworm rearer's, Grainage entrepreneur, yarn producers and weavers) from their slack labor and idle assets. Given the economic profile of households, many a times, this level of income contributes to almost $100 \%$ income enhancement of the household. Participating families would be able to invest their earning from project in debt redemption, recovery of mortgaged lands, buying pump sets, repairing or constructing houses and in educating their children in good schools.

The current state of affairs in tasar sector in the State warrant attention to improve infrastructure support in seed multiplication, promoting cultivation of host plants as block economic plantations, effective utilization of existing resources/infrastructure, extension support for effective dissemination of technologies/improved package of practices for cultivation, rearing of silkworms, upgrading skill levels of the farmers to undertake vanya sericulture activities for income generation, generating adequate trained manpower with technical knowledge and motivational skills, Monitoring, coordinating with line Departments, directing efforts for privatization and emphasizing the development of entrepreneurship in tasar silk sector, with the help of Community Based Organizations and Non Government Organizations. 


\section{International Journal of Science and Research (IJSR)}

ISSN (Online): 2319-7064

Index Copernicus Value (2013): 6.14 | Impact Factor (2014): 5.611

BAIF Holistic Approach in Livelihood Promotion

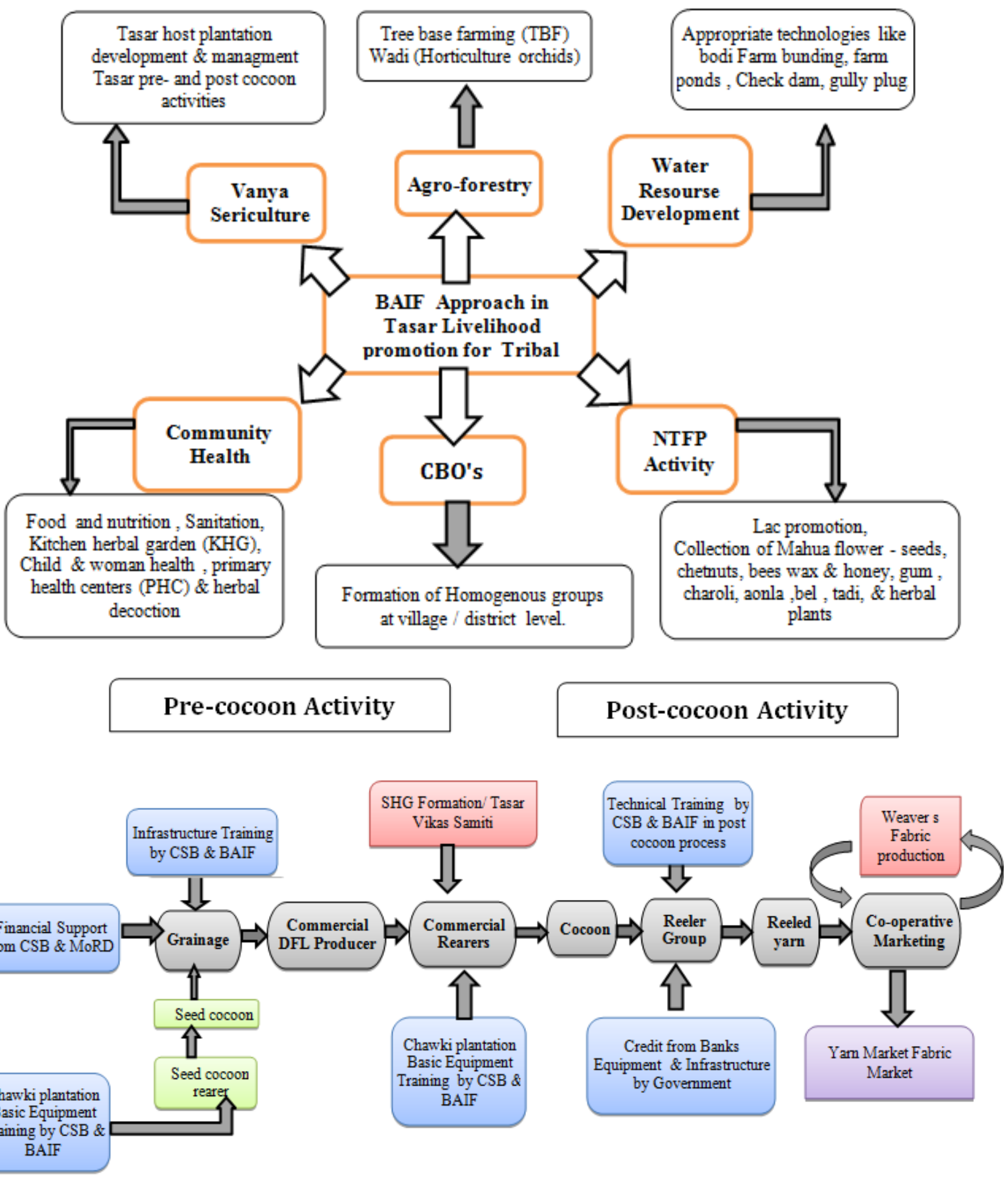

Volume 5 Issue 2, February 2016

www.ijsr.net 